\title{
THREE NEW SPECIES OF STEGANACARIDAE (ACARI, ORIBATIDA) FROM ZANZIBAR
}

\author{
Wojciech Niedbaea ${ }^{1}$ and Sergey G. Ermilov ${ }^{2}$ \\ ${ }^{1}$ Department of Animal Taxonomy and Ecology, Faculty of Biology \\ Adam Mickiewicz University in Poznań, ul. Umultowska 89, 61-614 Poznań, Poland; \\ E-mail: wojciech.niedbala@amu.edu.pl https://orcid.org/0000-0003-3772-0493 \\ ${ }^{2}$ Tyumen State University, Lenina str. 25, 625000 Tyumen, Russia; \\ E-mail: ermilovacari@yandex.ru; http://orcid.org/0000-0002-0913-131X
}

The present study is based on ptyctimous oribatid mite material collected from Zanzibar (Tanzania) in 2018. A list of identified taxa, including eight species from six genera and three families, is provided; of these, three new species of Steganacaridae (Steganacarus (Steganacarus) khaustovi Niedbała sp. n., Arphthicarus alius Niedbała sp. n. and Arphthicarus rectus Niedbała sp. n.) are described.

Key words: ptyctimous mites, fauna, systematics, morphology, Tanzania.

\section{INTRODUCTION}

Zanzibar is a semi-autonomous region of Tanzania. It is composed of the Zanzibar Archipelago in the Indian Ocean, $25-50 \mathrm{~km}$ off the coast of the mainland, and consists of many small islands and two large ones: Unguja (the main island, referred to informally as Zanzibar) and Pemba Island. Until present, the ptyctimous mites (Acari, Oribatida) of Tanzania are largely unknown (e.g., Starý 1988, NiedbaŁa \& Starý 2015, NiedbaŁa 2017) and records from Zanzibar were lacking so far.

Our present work is based on material collected from Zanzibar in 2018. The primary goal of the paper is to present a list of the identified taxa. In the course of a taxonomic identification, we found three new species from the family Steganacaridae, belonging to the genera Steganacarus Ewing, 1917 (one species) and Arphthicarus Niedbała, 1994 (two species). The secondary goal of the paper is to describe and illustrate these new species. The generic characters and identification keys of Arphthicarus and Steganacarus were presented by NiedbaŁA (e.g., 2000, 2001, 2004). The data on geographical distribution of these genera were summarized in NiedbaŁA and Liu (2018). 


\title{
MATERIAL AND METHODS
}

Oribatid mite material was collected during the Russian-Tanzanian expedition in 2018: Tanzania, Zanzibar, litter in a single locality of a mixed forest, $06^{\circ} 16^{\prime} 46.2^{\prime \prime} \mathrm{S}$, $039^{\circ} 25^{`} 41.0^{\prime}$ E, 8 m a.s.1., 2.II.2018 by A. A. Khaustov \& S. G. Ermilov.

Litter was collected by using a manual method. Mites were extracted into $75 \%$ ethanol using Berlese's funnels without electric lamps in laboratory conditions.

Specimens were mounted in lactic acid on temporary cavity slides for measurement and illustration. Body length was measured in lateral view, from the tip of the rostrum to the posterior edge of the notogaster. Notogastral width refers to the maximum width of the notogaster in dorsal view. Lengths of body setae were measured in lateral aspect. All body measurements are presented in micrometers.

The identification and illustrations of mite specimens were performed under a phase contrast microscope "Olympus BX50", equipped with a drawing attachment.

Morphological terminology used in this paper follows that of F. Grandjean: see Travé and Vachon (1975) for references, and Norton \& Behan-Pelletier (2009), for overview.

The following abbreviation for the deposition of the type material is used: DATE Department of Animal Taxonomy and Ecology, Adam Mickiewicz University in Poznań, Poland.

\section{SYSTEMATICS \\ List of identified taxa}

\author{
Mesoplophoridae Ewing \\ Mesoplophora (Mesoplophora) africana Balogh: 54 specimens \\ Euphthiracaridae Jacot \\ Acrotritia ardua (C. L. Koch): two specimens \\ Steganacaridae Niedbała \\ Plonaphacarus kugohi (Aoki): three specimens \\ Steganacarus (Steganacarus) khaustovi Niedbała sp. n.: one specimen \\ Arphthicarus alius Niedbała sp. n.: nine specimens \\ Arphthicarus rectus Niedbała sp. n.: eight specimens \\ Atropacarus (Hoplophorella) hamatus (Ewing): 21 specimens \\ Atropacarus (Atropacarus) striculus (C. L. Koch): one specimen
}

\section{Descriptions}

\section{Steganacarus (Steganacarus) khaustovi Niedbała sp. n.}

(Fig. 1A-J)

Measurements. Species with medium body size. Holotype. Prodorsum: length 394, width 209, height 121. Prodorsal setae: ss 63, in 30, le 18, ro 20, ex 12.6. Notogaster: length 515, width 343, height 348. Notogastral setae: $c_{1}$ and $h_{1} 51, c_{1} / c_{1}-d_{1}=0.4, p s_{1} 58$. Genitoaggenital plate $139 \times 111$. Ano-adanal plate $157 \times 96$; anal and adanal setae: $x_{1} 13, x_{2} 15, x_{3}$ $18, x_{4} 30$.

Integument. Colour brown. Surface of body sculptured, covered with widely spaced concavities. 


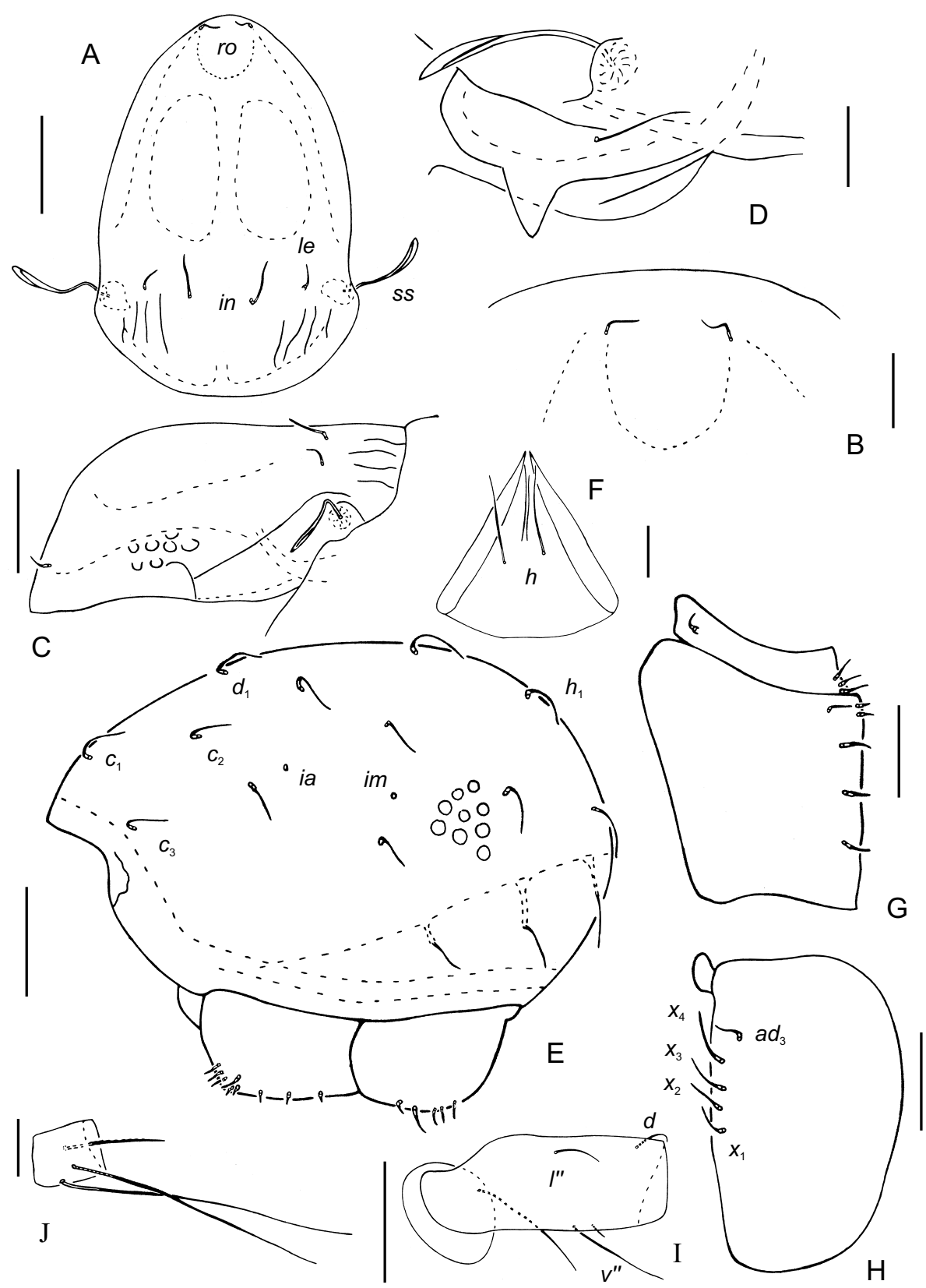

Fig. 1. Steganacarus (Steganacarus) khaustovi Niedbała sp. n. (holotype): A = prodorsum, dorsal view; $\mathrm{B}=$ rostrum; $\mathrm{C}=$ prodorsum, lateral view; $\mathrm{D}=$ fragment of prodorsum with sensillus and exobothridial setae; $\mathrm{E}=$ opisthosoma, lateral view; $\mathrm{F}=$ mentum of subcapitulum; $\mathrm{G}=$ right genito-aggenital plate; $\mathrm{H}=$ left ano-adanal plate; $\mathrm{I}=$ trochanter and femur of leg I; $\mathrm{J}=$ tibia of leg IV. Scale bars $100 \mu \mathrm{m}(\mathrm{A}, \mathrm{C}, \mathrm{E}), 50 \mu \mathrm{m}(\mathrm{B}, \mathrm{G}, \mathrm{H}), 25 \mu \mathrm{m}(\mathrm{D}, \mathrm{F}, \mathrm{I}, \mathrm{J})$ 
Prodorsum with distinct median crista. Lateral carinae present. Posterior furrows well marked. Sigillar fields narrow connected in anterior part, posterior of rostral setae deep sinus present. Sensilli rather long, with narrow pedicel and fusiform head, rough. Other setae small, setiform. Relative length of setae: $s s>$ in $>r o>l e>e x$.

Notogaster with 15 pairs of short $\left(c_{1}<c_{1}-d_{1}\right)$, setiform, smooth setae. Setae $c_{1}$ and $c_{3}$ slightly remote from anterior margin, $c_{1}$ more than setae $c_{3} ; c_{2}$ far away from margin. Vestigial setae $f_{1}$ invisible because of strong sculpturing. Two pairs of lyrifissures $i a$ and $i m$ present.

Ventral region. Setae $h$ of mentum very long, considerably longer than distance between them. Genitoaggenital plates each with nine genital setae with formula: $6(4+2): 3$. Ano-adanal plates with five pairs of setae; setae at the paraxial border decrease in length posteriorly, setae $a d_{3}$ very short, located near paraxial border.

Legs. Formulas of setae and solenidia of "complete type" (NiedbaєA 2000). Setae $d$ on femora I slightly remote from distal end of article, $l$ " situated posteriorly of setae $v$.

Holotype: Tanzania, Zanzibar, litter in the mixed forest, $06^{\circ} 16^{\prime} 46.2^{\prime \prime S}, 039^{\circ} 25^{\prime} 41.0^{\prime \prime} \mathrm{E}$, $8 \mathrm{~m}$ a.s.l., 2.II.2018 (A. A. Khaustov \& S. G. Ermilov).

Type deposition. The holotype (in ethanol with drop of glycerol) is deposited in DATE.

Etymology. The species is dedicated to the well-known acarologist Dr. Alexander A. Khaustov (Tyumen State University, Tyumen, Russia) for his extensive contributions to our knowledge of mites.

Remarks. The new species is easely distinguishable from other species of Steganacarus (Steganacarus) of the Afrotropical region (NiedbA£A \& LiU 2018) by the presence of very short, setiform setae of the body and the connected sigillar fields of the prodorsum.

\section{Arphthicarus alius Niedbała sp. n.}

(Fig. 2A-I)

Measurements. Species with rather big body size. Holotype. Prodorsum: length 338, width 227, height 172. Prodorsal setae: ss 101, in 99, le 51, ro 58. Notogaster: length 757, width 505, height 515. Notogastral setae: $c_{1}$ 202, $c_{1} / c_{1}-d_{1}=1.0, d_{1} 159, e_{1} 152, h_{1}$ 190, ps 202. Genito-aggenital plate $215 \times 152$. Ano-adanal plate $215 \times 139$. Measurements of paratypes. Prodorsum: length 303-328, height 136-156. Notogaster: length 616-677, height 374-465.

Integument. Colour light brown. Surface of body covered with deep concavities.

Prodorsum without lateral carinae. Posterior furrows present. Median crista present. Sigillar fields invisible because of strong sculpturing and median crista. Sensilli long, narrow, stick-shaped, smooth, obtuse distally. Interlamellar setae rather long, semi-erect, robust, covered with small spines in distal half, similar to notogastral setae. Lamellar setae robust, rough, pointed distally, shorter than interlamellar setae (in/le $=1.9)$. Rostral setae also robust, procumbent, rough, directed inwards, pointed distally. Exobothridial setae vestigial. Relative length of setae: $s s>$ in $>$ ro $>l e$.

Notogaster with 15 pairs of rigid, rather long $\left(c_{1}=c_{1}-d_{1}\right)$, distally slightly obtuse (visible under high magnification) setae covered with small spines in distal half. Dorsal setae slightly longer than laterals. Setae $c_{1}$ and $c_{3}$ slightly remote from anterior margin, setae $c_{2}$ far away from margin. Vestigial setae $f_{1}$ invisible because strong sculpture. All four pairs of lyrifissures $i a, i m$, ip and ips present; lyrifissures im and ip located next to each other. 


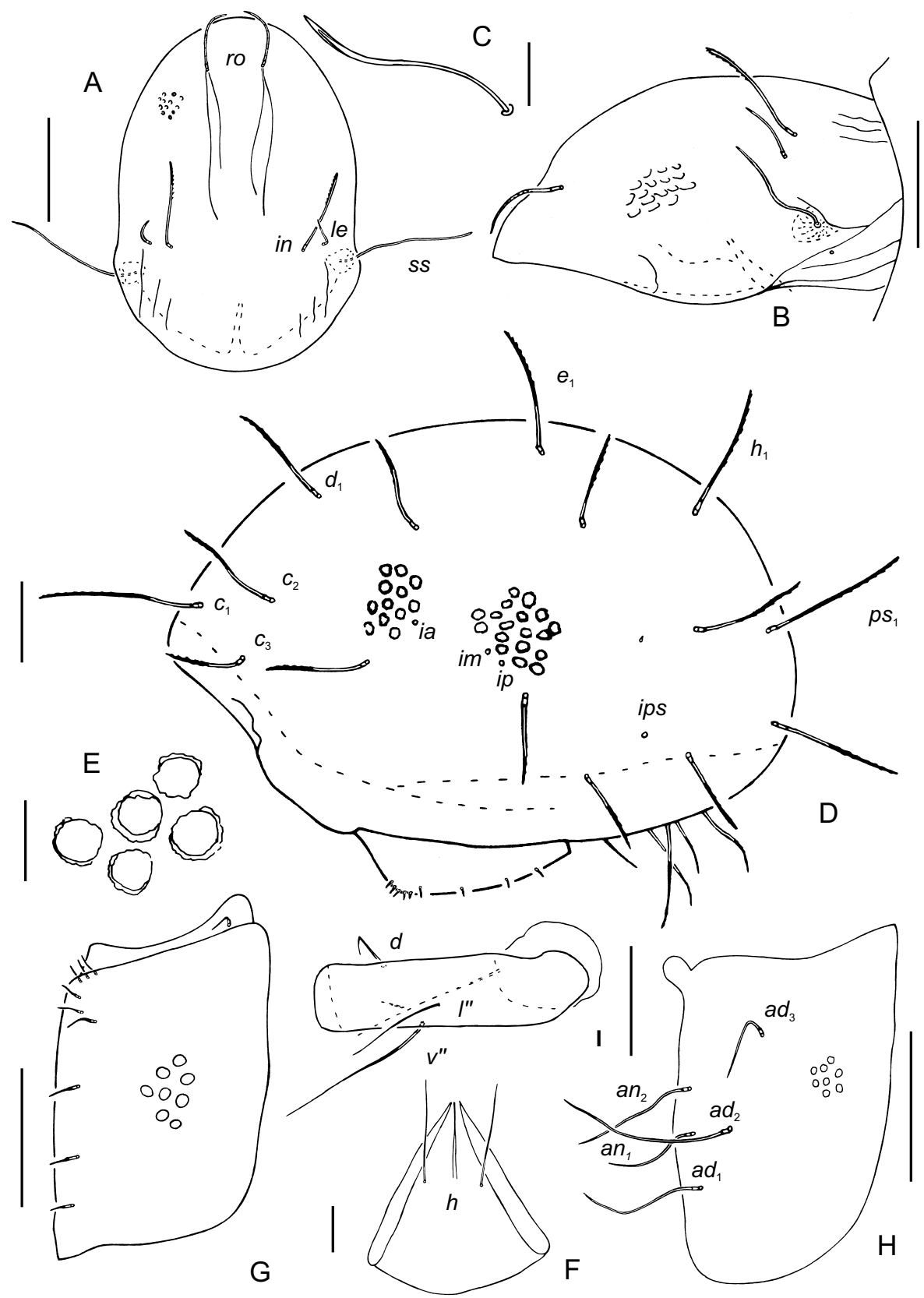

Fig. 2. Arphthicarus alius Niedbała sp. $\mathrm{n}$. (holotype): $\mathrm{A}=$ prodorsum, dorsal view; $\mathrm{B}=$ prodorsum, lateral view; $\mathrm{C}=$ sensillus of one paratype; $\mathrm{D}=$ opisthosoma, lateral view; $\mathrm{E}=\mathrm{con}-$ cavities of notogaster, magnification $\times 400 ; \mathrm{F}=$ mentum of subcapitulum; $\mathrm{G}=$ left genitoaggenital plate; $\mathrm{H}=$ left ano-adanal plate; $\mathrm{I}=$ trochanter and femur of leg $\mathrm{I}$. Scale bars 100 $\mu \mathrm{m}(\mathrm{A}, \mathrm{B}, \mathrm{D}, \mathrm{G}, \mathrm{H}), 25 \mu \mathrm{m}(\mathrm{C}, \mathrm{E}, \mathrm{F}, \mathrm{I})$ 
Ventral region. Setae $h$ of mentum considerably longer than distance between them. Genito-aggenital plates with nine pairs of setae with formula: 6(4+2): 3. Ano-adanal plates each with five rough setae, two anal and three adanal. Setae $a d_{2}$ longest and thickest, $a d_{3}$ smallest, setae $a n_{1}$ shorter than $a n_{2}$.

Legs. Formulas of setae and solenidia of "complete type" (NiedbaєA 2000). Setae $d$ on femora I curved distally, situated remote from distal end of article, $l$ " situated posteriorly of setae $v$.

Holotype and 8 paratypes: Tanzania, Zanzibar, litter in the mixed forest, $06^{\circ} 16^{\prime} 46.2^{\prime \prime} \mathrm{S}$, $039^{\circ} 25^{\prime} 41.0^{\prime \prime}$ E, 8 m.a.s.1., 2.II.2018 (A. A. Khaustov \& S. G. Ermilov).

Type deposition. The holotype and 8 paratypes (all in ethanol with drop of glycerol) are deposited in DATE.

Etymology. The specific epithet alius is Latin meaning "another" and alludes to morphological differences of the new species from other afrotropical Arphthicarus species.

Remarks. The new species is distinguishable by the presence of interlamellar setae of medium size and quite long lamellar setae, ratio $=1.9$. In other afrotropical species (NiedbaŁA \& Liv 2018) of Arphthicarus lamellar setae show different shapes and are much shorter than the interlamellar setae (only in $A$. notatus Niedbała, 2001 setae are similar in length, but also similar in shape). In addition, setae $a n_{1}$ of new species is shorter than $a n_{2}$, the notogastral setae $c_{1}$ similar in length as setae $p s_{1}$, the median crista of prodorsum is present, and lyrifissures im and ip are located next to each other.

\section{Arphthicarus rectus Niedbała sp. n.}

(Fig. 3A-G)

Measurements. Species with rather small body size. Holotype. Prodorsum: length 195, width 144, height 76. Prodorsal setae: ss 73, in 61, ro 35 . Notogaster: length 374, width 257, height 232. Notogastral setae: $c_{1} 53, c_{1} / c_{1}-d_{1}=0.65, d_{1}, e_{1}, h_{1} 40, p s_{2} 34$. Genito-aggenital plate $101 \times 96$. Ano-adanal plate $162 \times 104$. Measurements of paratypes. Prodorsum: length 157-195, height 56-66. Notogaster: length 273-384, height 167-227.

Integument. Colour light brown. Body surface covered with deep concavities.

Prodorsum. Lateral carinae absent. Posterior furrows present. Sigillar fields short, median field large. Sensilli long, slightly sickle-shaped, with narrowly fusiform head covered with small cilia. Interlamellar setae rather long, erect, robust, covered with small spines in distal half, similar to notogastral setae. Lamellar and exobothridial setae vestigial. Rostral setae erect, removed from each other, pointed distally, rough. Relative length of setae: ss $>$ in $>$ ro.

Notogaster with 15 pairs of rigid, rather short $\left(c_{1}<c_{1}-d_{1}\right)$, distally slightly obtuse (visible under high magnification) setae covered with small spines in distal half. Dorsal setae slightly longer than laterals. Setae $c_{1}$ and $c_{3}$ slightly remote from anterior margin, setae $c_{1}$ more than $c_{3} ; c_{2}$ much distant from margin. Vestigial setae $f_{1}$ located slightly posteriorly of $h_{1}$. All four pairs of lyrifissures ( $i a, i m$, ip and ips) present. 


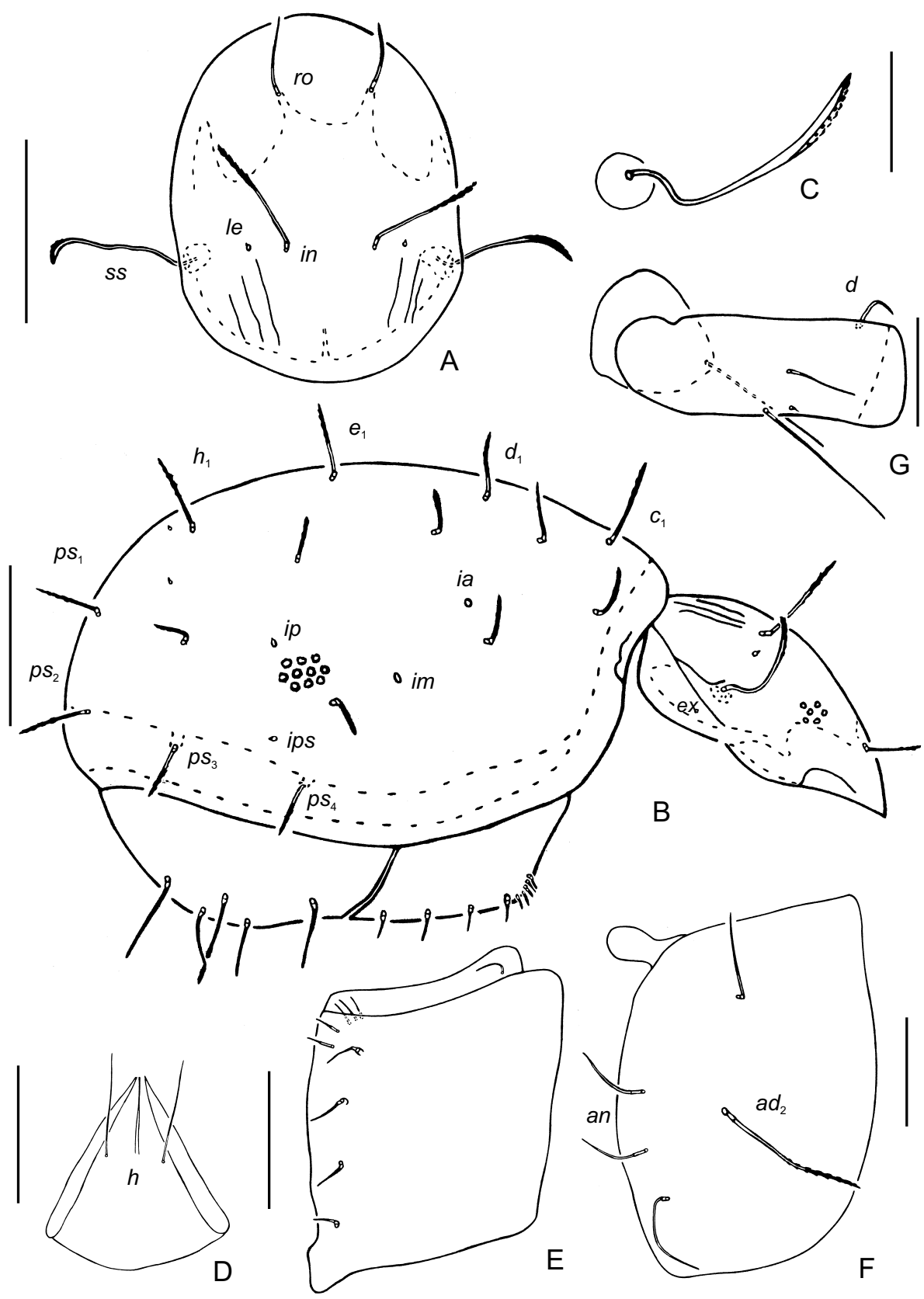

Fig. 3. Arphthicarus rectus Niedbała sp. n. (holotype): $\mathrm{A}=$ prodorsum, dorsal view; $\mathrm{B}=$ prodorsum and opisthosoma, lateral view; $C=$ sensillus; $D=$ mentum of subcapitulum; $E=$ left genito-aggenital plate; $F=$ left ano-adanal plate; $G=$ trochanter and femur of leg I. Scale bars $100 \mu \mathrm{m}(\mathrm{A}, \mathrm{B}), 50 \mu \mathrm{m}(\mathrm{E}, \mathrm{F}), 25 \mu \mathrm{m}(\mathrm{C}, \mathrm{D}, \mathrm{G})$ 
Ventral region. Setae $h$ of subcapitulum considerably longer than distance between them. Arrangement of genital setae: $6(4+2): 3$. Ano-adanal plate with five pairs of setae, $a d_{2}$ covered with small spines in distal half, longest and thickest, anal setae smallest.

Legs. Formulas of setae and solenidia of "complete type" (NiedbaєA 2000). Setae $d$ on femora I curved distally, slightly remote from distal end of article.

Holotype and 7 paratypes: Tanzania, Zanzibar, litter in the mixed forest, $06^{\circ} 16^{\prime} 46.2^{\prime \prime} \mathrm{S}$, $039^{\circ} 25^{`} 41.0^{\prime \prime} \mathrm{E}, 8 \mathrm{~m}$ a.s.l., 2.II.2018 (A. A. Khaustov \& S. G. Ermilov).

Type deposition. The holotype and 7 paratypes (all in ethanol with drop of glycerol) are deposited in DATE.

Etymology. The specific epithet of the new species is derived from Latin rectus and alludes to erect interlamellar and rostral setae.

Remarks. The new species is similar to Arphthicarus ethiopicus Niedbała, 2008 from Ethiopia by the shape and length of sensilli and notogastral setae, widely spaced rostral setae, number and location of lyrifissures, location of vestigial setae $f_{1}$, shape and location setae of ano-adanal plates, but differs from the latter by the presence of posterior furrows on prodorsum (versus absent in A. ethiopicus), erect, shorter rostral setae (versus longer and procumbent), vestigial lamellar setae (versus minute lamellar setae), length of setae $h$ of subcapitulum longer (versus shorter than distance between them), arrangement of genital setae: 4+2: 3 (versus 4+1:4) and location setae $d$ and $l$ " of femora I more posteriorly in A. ethiopicus.

The new species is also similar to Arphthicarus indiligens (Niedbała, 1984) from Malawi by the shape and length of prodorsal sigillary fields, the shape of sensilli, erect and widely distanced rostral setae, posterior furrows of prodorsum present, presence of four pairs of notogastral lyrifissures, arrangement of anal and adanal setae, but differs from the latter by shorter interlamellar, rostral and notogastral setae (versus longer $A$. indiligens), lamellar setae vestigial (versus not vestigial), absence of lateral carinae on the prodorsum (versus carinae present), setae $c_{2}$ distant from anterior margin (versus near margin), and genital setae $g_{6}$ are located slightly below of $g_{5}$ (versus setae $g_{6}$ are located slightly below setae $g_{3}$ ).

Acknowledgements - We cordially thank three anonymous reviewers for the valuable comments. The reported study was funded by the Russian Foundation for Basic Research (RFBR) according to the research project No. 18-04-00096. 


\section{REFERENCES}

EwING, H. E. (1917): A synopsis of the genera of beetle mites with special reference to the North American fauna. - Annals of the Entomological Society of America 10: 117-132. https://doi.org/10.1093/aesa/10.2.117

Niedba€A, W. (1984): Trois Phthiracaridae nouveaux de l'Afrique Centrale (Acari, Oribatida). - Revue de Zoologie Africaine 98: 644-653.

Niedba€A, W. (1994): Supplement to the classification of Phthiracaroidea, with redescriptions and descriptions of some species (Acari, Oribatida, Euptyctima). - Genus 5: $1-152$.

Niedba€A, W. (2000): The ptyctimous mites fauna of the Oriental and Australian regions and their centres of its origin (Acari: Oribatida). - Genus (Suppl.): 1-493.

NiedbaєA, W. (2001): Study on the diversity of ptyctimous mites (Acari, Oribatida) and quest for centres of its origin: the fauna of the Ethiopian region. - Monographs of the Upper Silesian Museum 3: 1-245.

Niedba€A, W. (2004): Ptyctimous mites (Acari, Oribatida) of the Neotropical region. - Annales Zoologici 54: 1-288.

NiedbaŁA, W. (2008): Description of a new species of ptyctimous mites (Acari, Oribatida) from Ethiopia and a checklist of ptyctimous mites of the Afrotropical Region. - Tropical Zoology 21: 1-9.

Niedba€A, W. (2017): Ptyctimous mites (Acari, Oribatida) of Tanzania. - Acarologia 57: 9571072. https://doi.org/10.1051/acarologia/20164149

Niedba€A, W. \& Liu, D. (2018): Catalogue of ptyctimous mites (Acari, Oribatida) of the World. - Zootaxa 4393: 1-238. https://doi.org/10.11646/zootaxa.4393.1.1

Niedba€A, W. \& Starý, J. (2015): New species of the superfamily Euphthiracaroidea (Acari, Oribatida) from Madagascar and Tanzania. - Journal of Natural History 49: 1689-1701. https://doi.org/10.1080/00222933.2014.976670

Norton, R. A. \& Behan-Pelletier, V. M. (2009): Suborder Oribatida. Chapter 15. Pp. 430564. - In: Krantz, G. W. \& Walter, D. E. (eds): A manual of acarology. Texas Tech University Press, Lubbock.

Starý, J. (1988): Pocsia kunsti n. sp. from Tanzania (Acari: Oribatida: Euphthiracaridae). Věstník československé společnosti zoologické 52: 44-47.

Travé, J. \& Vachon, M. (1975): François Grandjean. 1882-1975 (Notice biographique et bibliographique). - Acarologia 17: 1-19.

Received February 27, 2019, accepted May 1, 2019, published August 12, 2019 


\title{
The oribatid species described by Berlese (Acari)
}

\author{
by MAHUNKA, S. and L. MAHUNKA-PAPP
}

The authors had the opportunity for years to study the Oribatid species described by Berlese currently deposited in the Istituto Sperimentale per la Zoologia Agraria at Florence. The results of this series of studies are summarized in this volume.

The volume begins with an essay-like Introduction heavily relying on subjective opinions discussing the general questions of Oribatology. The following section lists Berlese's species placed in the modern system helping the specialists with morphological notes and many drawings; here also the condition of the specimens is discussed and lectotypes are designated.

The third, large section is the catalogue proper, wherein all the species are listed in the systematic order together with their combination and synonymic names. Here one may find all the literature data, usually missing from ordinary works, with reference to Description and Taxonomy, Distribution, with special emphasis on Catalogues whose references are partly unreliable. Where it was deemed necessary further information are added under the heading of Remarks. The volume closes with a very detailed list of literature.

ISBN 9637093273

325 pages with several figures. Soft bound.

Hungarian Natural History Museum, Budapest, 1995

Price: 40 US dollars excluding package and postage

Order should be sent

to the Hungarian Natural History Museum, Library

Baross u. 13, Budapest, H-1088 Hungary

Fax: (36-1) 3171669 